\title{
UMA REFLEXÃO SOBRE A REDE MUNDIAL DE COMPUTADORES
}

por Guilherme Paiva de Carvalho*

CASTELLS, Manuel. A galáxia da Internet: reflexões sobre a Internet, os negócios e a sociedade. Trad. Maria Luiza X. de A. Borges. Rio de Janeiro: Jorge Zahar, 2003. 244 p.

Nascido na Espanha em 1942, Manuel Castells lecionou durante 12 anos na Universidade de Paris, ingressando, em 1979, na Universidade da Califórnia em Berkeley, onde é professor de Sociologia e Planejamento Regional. Em A galáxia da Internet, Castells analisa as mudanças no mundo empresarial, as inovações na Economia e na Política a partir da utilização da Internet como sistema de comunicação global, traçando uma geografia da sociedade em rede. A Internet aparece como tema central do livro que é composto por nove capítulos, nos quais o autor reflete sobre a história e a cultura da Internet, as transformações dos modos de interação social, a multimídia, além de questões relacionadas ao planejamento urbanístico e ao acesso à rede mundial de computadores.

No primeiro capítulo, Castells retoma a história da Internet desde a formação da Arpanet no final de 1960, mostrando como ela surge de um projeto do Departamento de Defesa norte-americano que, com o objetivo de superar a tecnologia soviética, criou, em 1958,

* Doutorando em Sociologia na Universidade de Brasília (UnB). 
a Advanced Research Projects Agency (ARPA) para desenvolver uma rede interativa de computadores (p. 14). Pesquisas realizadas conjuntamente por órgãos governamentais, universidades e centros de pesquisa resultaram na interconexão de computadores em rede. Dispondo de uma arquitetura de protocolos abertos, a rede permitia que os usuários participassem do aperfeiçoamento de softwares para a Internet. A partir do software Enquire, desenvolvido por Berners-Lee, foi produzida a World Wide Web (p. 18), um sistema de hipertexto no qual informações poderiam ser acrescentadas pelos usuários e acessadas por computadores que estivessem conectados à rede. Introduzindo novas versões do software de navegação da web, a Netscape Communications disponibilizou, em 1994, o Netscape Navigator. Posteriormente, a Microsoft lançou o Windows 95 com o Internet Explorer, um navegador para a web. A Internet surge na metade da década de 1990 como um sistema de comunicação flexível e descentralizado. A arquitetura aberta proporcionava a cooperação dos usuários. Assim, a flexibilidade e a liberdade foram valores importantes para o desenvolvimento da Internet. Liberdade, solidariedade e cooperação são concepções que compõem a cultura de cientistas, engenheiros, estudantes de pós-graduação e dos primeiros usuários da rede que participaram conjuntamente da criação da Internet.

Castells analisa a cultura da Internet no segundo capítulo do livro, ressaltando a importância da abertura do código-fonte para o aperfeiçoamento dos softwares da Internet, além de tratar da cultura hacker, evidenciando que, apesar de ter influenciado valores e hábitos da cultura da Internet, a tradição acadêmica - baseada na busca por prestígio e reconhecimento dos pares - foi aliada aos valores dos hackers, especialistas na programação e interconexão de computadores que desempenharam um papel relevante no desenvolvimento da Internet. De acordo com Castells (p. 38), “a cultura hacker [...] diz respeito ao conjunto de valores e crenças que emergiu das redes de programadores de computador que interagiam online [...]" na modificação do software, aprimorando o sistema operacional da Internet. A cultura hacker tem como base uma 
concepção "tecnomeritocrática" fundada na busca por excelência e melhoria do desempenho tecnológico. É preciso ter liberdade para criar, se apropriar do conhecimento e redistribuí-lo na rede. Sendo assim, a liberdade constitui um valor fundamental para a cultura hacker. A formação de redes tornar-se-ia um padrão de comportamento habitual na Internet, e que vem sendo disseminado em diversos setores da sociedade. Há ainda uma análise acerca da cultura empresarial que se difunde na Internet, na qual idéias inovadoras e criatividade aparecem como valores essenciais.

Reflexões sobre questões relacionadas com o comércio eletrônico, a formação e a estrutura organizacional de empresas em rede, as mudanças nos mercados financeiros, a flexibilidade do trabalho e a produtividade compõem o terceiro capítulo do livro. O aparecimento de empresas ".com" alterou o comércio. Empresas passaram a utilizar a Internet para comunicação e processamento de informações, dispondo de uma estruturação organizacional baseada na rede (p. 57). O comércio eletrônico e as empresas online também modificaram as relações econômicas. Em algumas firmas, atividades dos setores de produção e distribuição são realizadas através da Internet. Além disso, redes de computadores integraram os mercados financeiros, formando um mercado global interdependente e transnacional. No âmbito do trabalho, há uma exigência de maior qualificação profissional, além da necessidade de alto nível educacional. A flexibilidade vem direcionando as relações de trabalho no contexto da nova economia global que apresenta ainda um crescimento significativo da produtividade.

O quarto capítulo tem como enfoque a sociabilidade. Novas formas de interação social que apareceram com o uso da Internet são analisadas. Castells expõe questões concernentes à formação de identidades e representação de papéis sociais na Internet (p. 99) e discute, também, a problemática do individualismo na rede.

Tomando como referência o uso da Internet, o quinto e o sexto capítulo trazem uma reflexão sobre a relação entre sociedade civil e Estado, questão que envolve discussões concernentes à 
privacidade dos usuários da rede e ao problema da liberdade no sistema de comunicação global. No quinto capítulo, Castells menciona os movimentos sociais que adotaram a Internet para a defesa de suas propostas. Valores culturais aparecem como base dos movimentos sociais que se articulam na rede para alterar "códigos de significado nas instituições e na prática [...]” social (p. 116). Com a Internet, a participação política dos cidadãos através da rede pode redefinir a democracia. Castells cita a Cidade Digital de Amsterdã como um exemplo de revitalização da esfera pública. Informações sobre ações do governo e a possibilidade de interatividade com os cidadãos podem ser viabilizadas pela Internet. No entanto, com a Internet também surgem novas estratégias de guerra que ameaçam a soberania dos Estados. A invasão de hackers a computadores de órgãos governamentais, ou ainda, a utilização da rede por criminosos e terroristas, preocupam as lideranças políticas. Se, por um lado, há um interesse de governos em desenvolver tecnologias de controle da Internet, por outro viés, a rede de computadores tem potencialidade para a difusão de valores humanistas e a democratização.

As tecnologias de controle e vigilância, mencionadas no sexto capítulo do livro, restringem a liberdade e a privacidade dos usuários da Internet que podem ter seus e-mails registrados e controlados por governos (p. 145). O Estado tem sua soberania abalada pelo fluxo de informações. Castells ressalta que para revigorar o poder, o G-8 adotou medidas para controle e policiamento dos provedores da Internet. Entretanto, a soberania continua oscilante já que, para o exercício do controle, os Estados têm que dividir o poder, constituindo, por fim, um Estado em rede (p. 147).

Castells discute as noções de multimídia e hipertexto no sétimo capítulo do livro, demonstrando que há uma convergência ainda restrita entre a Internet e a multimídia, apesar da difusão da televisão digital por todo o mundo. Por outro lado, a multimídia permitiu a divulgação de músicas pela Internet por intermédio do formato MP3. Videogames online, vídeos pornográficos, revistas eletrônicas comercializadas por serviços de assinatura e rádios virtuais também aparecem com destaque na Internet. Castells 
sustenta que não é possível afirmar que há um hipertexto entendido como sistema interativo de expressão de culturas presentes, passadas e futuras devido à falta de interesse comercial na formação de um hipertexto.

O oitavo capítulo apresenta uma geografia da Internet a partir da determinação de sua estrutura técnica, da distribuição espacial dos usuários, bem como da configuração econômica e urbanística das cidades na Era da Informação. Castells salienta o modo fragmentário de difusão do uso da Internet, baseado em padrões de riqueza, tecnologia e poder (p. 174). Pesquisas reforçam a constatação de que a Internet vem sendo bem mais difundida em áreas urbanas do que em áreas rurais. Há também uma concentração da provisão de conteúdo da Internet em regiões metropolitanas, onde as atividades que geram renda e oportunidades de emprego se encontram. As metrópoles continuam absorvendo a população urbana (p. 185). O trabalho em casa não é uma realidade na Era da Informação. De acordo com Castells, nos EUA, país que apresenta maior flexibilização do trabalho, estatísticas de 1997 mostravam que somente o percentual de 6,43\% da mão-de-obra trabalhava em casa (p. 190). Castells ainda se refere às tendências de modelos arquitetônicos e planejamento urbanístico que surgirão com a incorporação de sistemas eletrônicos de rede na construção de "ambientes inteligentes" (p. 193).

$\mathrm{O}$ acesso à Internet e o problema da exclusão social são tratados no nono capítulo do livro. A renda e o nível educacional das pessoas constituem a base para o acesso à Internet; além disso, há uma divisão dos usuários por etnia. Nos EUA, por exemplo, a maioria dos usuários é composta por brancos e a minoria por afroamericanos e hispânicos (p. 204). A deficiência física também constitui uma barreira para o acesso à Internet. Ademais, a difusão da Internet no mundo ocorre de modo desigual, concentrando-se na América do Norte, na Europa Ocidental e na Ásia, enquanto América Latina, Europa Oriental, Oriente Médio e África apresentam os índices mais baixos de acesso à Internet. 
Castells conclui que a Era da Internet traz novos desafios para a humanidade. Tais desafios estão correlacionados com a instabilidade no emprego, a deterioração do meio ambiente, a necessidade de regulação dos mercados e direcionamento da tecnologia, as desigualdades, a exclusão social e a educação. Castells critica o sistema educacional atual, sustentando que, na sociedade em rede, seria preciso instituir uma nova pedagogia, fundada na interatividade e no aprimoramento da capacidade de aprender e pensar. Contudo, apesar de ser visualizada como um desafio para a sociedade em rede, a questão da educação não é um tema central do livro, como o próprio autor reconhece na introdução. Esta lacuna não chega a atingir a riqueza de dados históricos e informações acerca da Era da Internet, fundamentais para as áreas da Sociologia, da Economia, da Administração, da Política e das Ciências da Computação. Castells ainda propõe uma reflexão sobre a nossa responsabilidade, enquanto seres humanos, no controle da tecnologia, sugerindo que para direcionar os artefatos tecnológicos será necessário nos conscientizarmos de que a democracia participativa e a mudança política são imprescindíveis para o enfrentamento dos desafios da sociedade em rede na Era da Informação. 